\title{
Source parameters estimation of 2003 Bam earthquake Mw 6.5 using empirical Green's function method, based on an evolutionary approach
}

\author{
Ahmad Nicknam ${ }^{1, *}$, Reza Abbasnia ${ }^{1}$, Yasser Eslamian ${ }^{1, * *}$, \\ Mohsen Bozorgnasab ${ }^{1}$ and Ehsan Adeli Mosabbeb ${ }^{2}$ \\ ${ }^{1}$ Civil Engineering Department, Iran University of Science and Technology, Tehran 16846, Iran. \\ ${ }^{2}$ Computer Engineering Department, Iran University of Science and Technology, Tehran 16846, Iran. \\ *e-mail: a_nicknam@iust.ac.ir \\ **e-mail: y_eslamian@iust.ac.ir
}

We determine the source parameters for 2003 (Mw 6.5) Bam, Iran, earthquake using an empirical Green's function summation approach to model ground motions recorded by two strong motion stations at approximately $45 \mathrm{~km}$ epicentral distance. We introduce a genetic algorithm technique to optimize the fit to observed elastic response spectra. The proposed genetic algorithm technique allows us to explore the sensitivity of the results to multiple source parameters, including hypocenter location, focal mechanism (Strike and Dip), P-wave velocity in depth, fault dimension and rupture and healing velocities.

We simulated the three components of seismogram at a far station, Mohammad-Abad station, by means of an inversion solution technique and predicted seismograms at another far station, Abaragh, incorporating the estimated model parameters. More agreement of our synthesized seismograms with those of the observed data in comparison with the results of other investigators confirms the reliability of estimated seismological parameters and the applicability of our technique.

A series of sensitivity analysis are performed for demonstrating the influence of individual model parameter variation on defined error value. Using the empirical Green's function summation method, our inferred source parameters provide the basis for predicting main shock shaking and guiding retrofitting efforts at sites, for example, the historical buildings in Arge-Bam site which were damaged during the 2003 Bam earthquake and strong motion data is unavailable.

\section{Introduction}

On December 26, 2003 an earthquake (Mw 6.5) struck the Bam city, one of the historical towns in Iran, causing large structural damage and loss of human life. It was reported by the UN Office for the Coordination of Humanitarian Affairs (OCHA) that the earthquake caused approximately 43,200 deaths of residents and approximately 20,000 injuries. About 75,600 people (14,730 households) were displaced and 25,000 dwellings were razed (EERI Special Earthquake Report 2004).

Bam is located on the eastern part of the Gowk fault and the western part of the strike slip fault systems bordering the Lut desert. Lut desert lies in the south-eastern part of Iran. On both eastern and western sides of Dasht-e Lut, there are systems of N-S right-lateral strike-slip faults that accommodate $\sim 13-16 \mathrm{~mm} / \mathrm{yr}$ of $\mathrm{N}-\mathrm{S}$ right-lateral shear on a part of the rigid Eurasia, between central

Keywords. The Bam earthquake; EGF method; genetic algorithm; seismological source parameters; response spectra. 


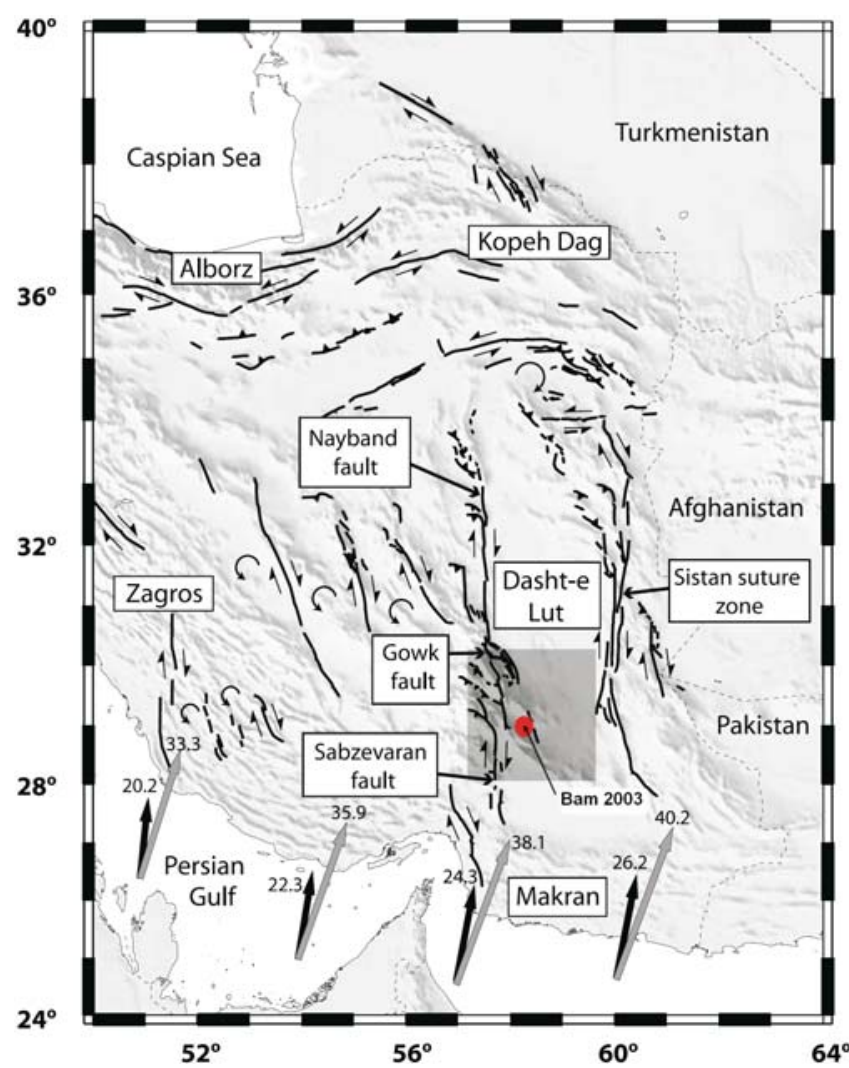

Figure 1. Shaded relief map of central and eastern Iran showing major faults (Funning et al 2005).

Iran and western Afghanistan (Jackson et al 2006) (figure 1). On the Gawk fault zone, several earthquakes have been occurred during the past couple of decades; in 1981 ( $\mathrm{Mw} 6.6$ and 7.0), 1989 (Mw 5.8) and 1998 (Mw 6.6). The coseismic surface ruptures and focal mechanisms of these earthquakes, together with their associated geomorphology, show the activity in this zone (Jackson et al 2006); however, historically, there are no recorded earthquakes at Bam. The notable point is that Arg-e-Bam, which was destroyed in the earthquake, belonged to centuries ago (Talebian et al 2004).

Field surveys that Talebian et al (2004) carried out in the week after the earthquake found no major surface rupture but showed small-scale fissuring along the fault trace south of the Posht-rud river, and along a $5 \mathrm{~km}$ lineament north of the river. These observations seemingly suggested that the rupture had occurred at a depth on the faults associated with the surface traces (Talebian et al 2004). Surprisingly, the more detailed studies by Talebian et al (2004) showed that the main rupture in the earthquake did not occur on fault relating to the obvious surface traces (dashed line), but on a fault further west (black line), in a region with complete absence of surface features (figure 2). This fault lies immediately south of the Bam and extends directly

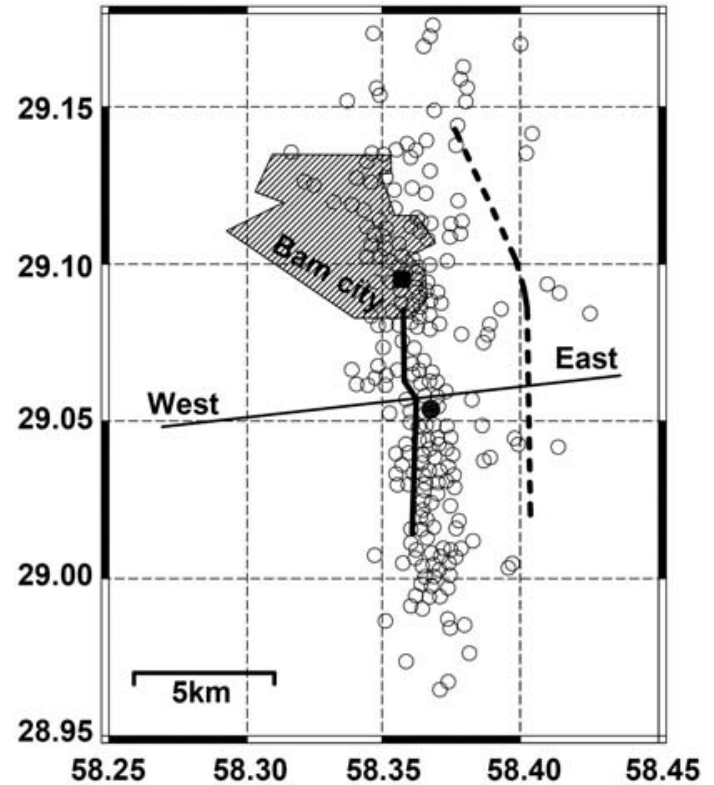

Figure 2. Hypocenter location reported by BHRC (black circle), causative fault location of the Bam earthquake (black line), and surface traces (dashed line). The small circles show aftershock locations (Jackson et al 2006).

beneath the city at its northern end (Talebian et al 2004).

\section{Synthetic seismogram generating methods}

There are a number of methods for estimating ground shaking in literature; theoretically, the first calculation of strong motions was made by Aki (1968) and Haskell (1969). They used kinematic source model propagating dislocation over a fault plane in an infinite homogeneous medium with five parameters, the fault length, fault width, rupture velocity, final offset of dislocation and rise time which were included in the model (e.g., Irikura 1983).

Point source method introduced by Brune (1970) and extended by Boore (1983) is widely used in ground motion modelling for engineering purpose. Despite the popularity of this approach, the point source approximation is unable to characterize key features of large earthquakes such as their long duration (Beresnev and Atkinson 2002). The finite fault method that is developed by Irikura (1983) and Beresnev and Atkinson (1997) can solve some of the problems of point source model such as the above aforementioned one; while it is believed that both methods suffer from modelling the dependence of amplitudes on the azimuth to the observation point, i.e., directivity effect and fling step (Beresnev and Atkinson 2002). Wennerberg (1990) 
used Joyner and Boore (1986)'s stochastic summation approach to describe the source with the empirical Green's functions. Whereas, probability distributions do not provide an extensive description of the phase effects of the finite source and do not generate similar time histories respect to the observed records.

The use of recordings of small events for studying large earthquakes was introduced by Hartzell (1978) as empirical Green's function (EGF). It is possible to generate synthetic ground motion assuming an appropriate scaling of the time histories and adding them proper delays for representing propagation of fault rupture (Anderson 2001). Although simple teleseismic body waves $(\mathrm{P}$ and $\mathrm{SH}$ direct waves) can be precisely and deterministically estimated, most parts of the seismograms cannot, and that is the reason of being helpful to use a smaller event, EGF, to take the propagation between the source and the receiver into account (Valle'e 2004).

The EGF approach can be applied both in direct and inverse problems. In direct problems, this technique is widely used in strong motion simulation of expected future events (Plicka 2003). Some seismologists like Irikura (1983), Joyner and Boore (1986), Kanamori et al (1993), Hutchings et al (2007) have utilized this approach to synthesize strong motions. In the inverse problems, adopted in this study, EGF helps to find the source information such as slip distribution on fault (Plicka 2003). Some investigators such as Mueller (1985), Frankel et al (1986), Mori and Frankel (1990), Velasco et al (1994), Courboulex et al (1997) and Plicka and Zahradnik (2002) have used this application of EGF. EGF model for which only limited numbers of small earthquakes are required so that the sum of their moments adds up to the moment of the large earthquake, is adopted in this study (Hutchings 1994).

Synthesizing strong ground motions requires considering effects of the path between the source and the receiver. One of the main merits of EGF approach stems in taking into account the effects of surface soil overlying bedrock, since it significantly modifies earthquake ground motions particularly in the high frequency range depending on the shear wave velocity and depth of the soil (Lam et al 2000). Hutchings (1991) used empirical Green's functions to constrain propagation path and site response information and proposed a range of simple kinematic rupture models to describe the source in predicting strong ground motion for the full time history. This simple earthquake model was tested by Jarpe and Kasameyer (1996) for the 1989 Loma Prieta earthquake with source parameters determined from different studies of the earthquake. Wu (1978) and Hutchings and Wu (1990) examined the theoretical relation between rupture parameters and synthesized seismograms using an exact solution to the representation relation, in the frequency and time domain that uses empirical Green's functions. This solution uses empirical Green's functions to obtain the Green's functions of the representation relation, allowing for completely synthetic rupture models (Hutchings 1994).

It is noticeable that, recording empirical Green's functions from all locations along a fault is not practically possible. Also, EGFs may originate from sources with a focal mechanism different from the desired mechanism, while Hutchings and $\mathrm{Wu}$ (1990) found that the variability in ground motion due to differences in source location and/or focal mechanism solutions are much less than that due to the site response. Hutchings $(1991,1994)$ and Jarpe and Kasameyer (1994) interpolated the source locations of empirical Green's functions to fill in the fault. They pointed out that this interpolation works quite well. Also, it is sufficient that the source events are located near the fault of interest and do not necessarily fall directly along the fault (Hutchings et al 1997).

Theoretical Green's functions method has been used for generating synthetic seismograms with appropriate accuracy. The isochrones integration method is widely used and very efficient for computing synthetic seismograms using far-field raytheory Green's functions (Bernard and Madariaga 1984; Spudich and Frazer 1984; Beroza and Spudich 1988).

Another method of generating broadband seismogram is Hybrid methods. These approaches are those types of generating synthetic seismograms which are obtained by combining, in the frequency range, the deterministic low-frequency waveforms with the high-frequency synthetics such as point source or finite-fault approaches. A modelling method for strong ground motion simulations, so called hybrid k-squared source modelling technique (HIC) has been developed, in that the rupture process is decomposed into slipping on the individual overlapping sub-sources of various sizes, distributed randomly on the fault plane. More detail is available in Gallovic and Brokeshova (2007). The source modelling method is combined with the discrete wave-number method (Bouchon 1981), yielding full-wavefield Green's functions.

This manuscript is organized as follows: next section explains the sources of uncertainty and how they are dealt with, in this work. Subsequent sections are allocated to source data and explaining the GA technique used. After that, the proposed technique and the far source simulation techniques 


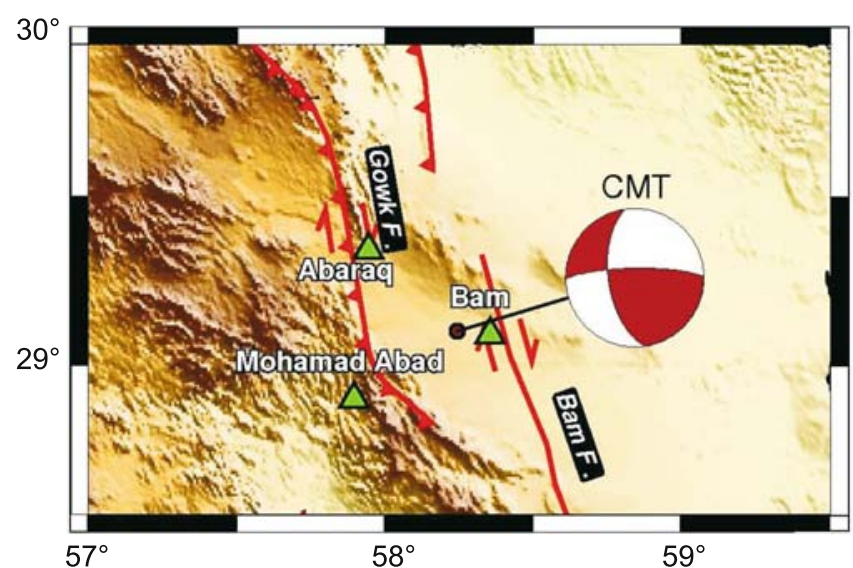

Figure 3. Location of stations, Mohammad-Abad and Abaragh, used in this study.

are explained. Then the estimated time series are compared with those of recordings. A sensitivity analysis is performed demonstrating the influence of estimated seismograms against the model parameters. Finally the paper ends with some conclusions which are suitably applicable for the Bam region.

\section{Sources of uncertainty in engineering problems}

Sources of uncertainty in engineering safety problems are classified into two major groups known as aleatory uncertainty (due to inherent randomness) and epistemic uncertainty (due to limited knowledge of mathematical form of the model used). The aleatory uncertainty is the result of the estimated seismological source parameters and the factors affecting the wave propagation and site amplification and the epistemic uncertainty is arisen from the mathematical formulation of the model.

GA is one of the most effective techniques for optimizing/reducing the above-mentioned two families of uncertainties (e.g., Naeim et al 2004). In this paper, GA is used to extract seismological parameters. Here, the parameters are bounded in specific ranges. Furthermore, different sub-faults dimensions and Brune correction (Hutchings et al
2007) are used. Incorporating the aforementioned parameters within predefined ranges is an example of optimizing/reducing the first type of uncertainty. Utilizing a number of predefined different sub-faults dimensions and Brune correction as well, are samples of confronting the second source of uncertainty.

\section{Source data}

A number of aftershocks, in the form of three components, have been recorded at some stations around the Bam earthquake epicenter during December 2003 earthquake (BHRC). The selected stations are sufficiently far away from the causative fault, so their recorded time histories were not influenced by near field problems. Figure 3 shows the location of the stations that are used in this study. The reason of selecting these two stations is that in these stations there exist sufficient reliable EGF records.

Some of the recorded aftershocks at these two stations were selected and are used for synthesizing strong motions and will be explained later on. Table 1 shows the selected stations along with their locations, the number of aftershocks recorded at each station and the site soil condition classified based on the Iranian standard no. 2800 (compatible with those of NEHRP Code 2001). Since the synthesis approach is based on site response from very small ground motions, it is only valid for linear material response. Therefore, soil nonlinearity is not taken into account in this study. This is the same assumption made in Hutchings et al (1997). Table 2 shows the aftershock names associated with event dates used as EGFs in the simulating seismogram at Mohammad-Abad and Abaragh stations.

\section{The proposed genetic algorithm based technique}

One of the best methods to achieve a nearly optimal solution in problems dealing with uncertainty and a lot of imprecise variables is known

Table 1. Station names, locations and number of EGFs recorded at each station for the 2003 Bam earthquake used in this study.

\begin{tabular}{lcccccc}
\hline & & & & \multicolumn{2}{c}{ Geological classification } \\
\cline { 3 - 6 } Station & $\begin{array}{c}\text { Longitude } \\
\text { (deg.) }\end{array}$ & $\begin{array}{c}\text { Latitude } \\
\text { (deg.) }\end{array}$ & $\begin{array}{c}\text { Orient. } \\
\text { L,T-90 }\end{array}$ & $\begin{array}{c}\text { No. of } \\
\text { EGF }\end{array}$ & $\begin{array}{c}\text { Standard } \\
\text { no. 2800* }\end{array}$ & $\begin{array}{c}\text { NEHRP } \\
\text { code }\end{array}$ \\
\hline Mohammad-Abad & 57.888 & 28.908 & N 350 E & 3 & II & C \\
Abaragh & 57.94 & 29.34 & 72 & 4 & - & - \\
\hline
\end{tabular}

* Iranian Code of Practice for Seismic Resistant Design of Buildings (Standard no. 2800). 
Table 2. Aftershocks at Mohammad-Abad and Abaragh stations used as EGFs in this study.

\begin{tabular}{lccc}
\hline Station & Event name & Event date & Mw \\
\hline \multirow{3}{*}{ Mohammad-Abad } & $3162 / 02$ & $26 / 12 / 2003$ & 4.6 \\
& $3555 / 01$ & $06 / 10 / 2004$ & 5.2 \\
Abaragh & $3555 / 02$ & $07 / 10 / 2004$ & 4.5 \\
& $3176 / 02$ & $26 / 12 / 2003$ & 5.1 \\
& $3176 / 03$ & $26 / 12 / 2003$ & 4.6 \\
& 3289 & $28 / 12 / 2003$ & 4.2 \\
\hline
\end{tabular}

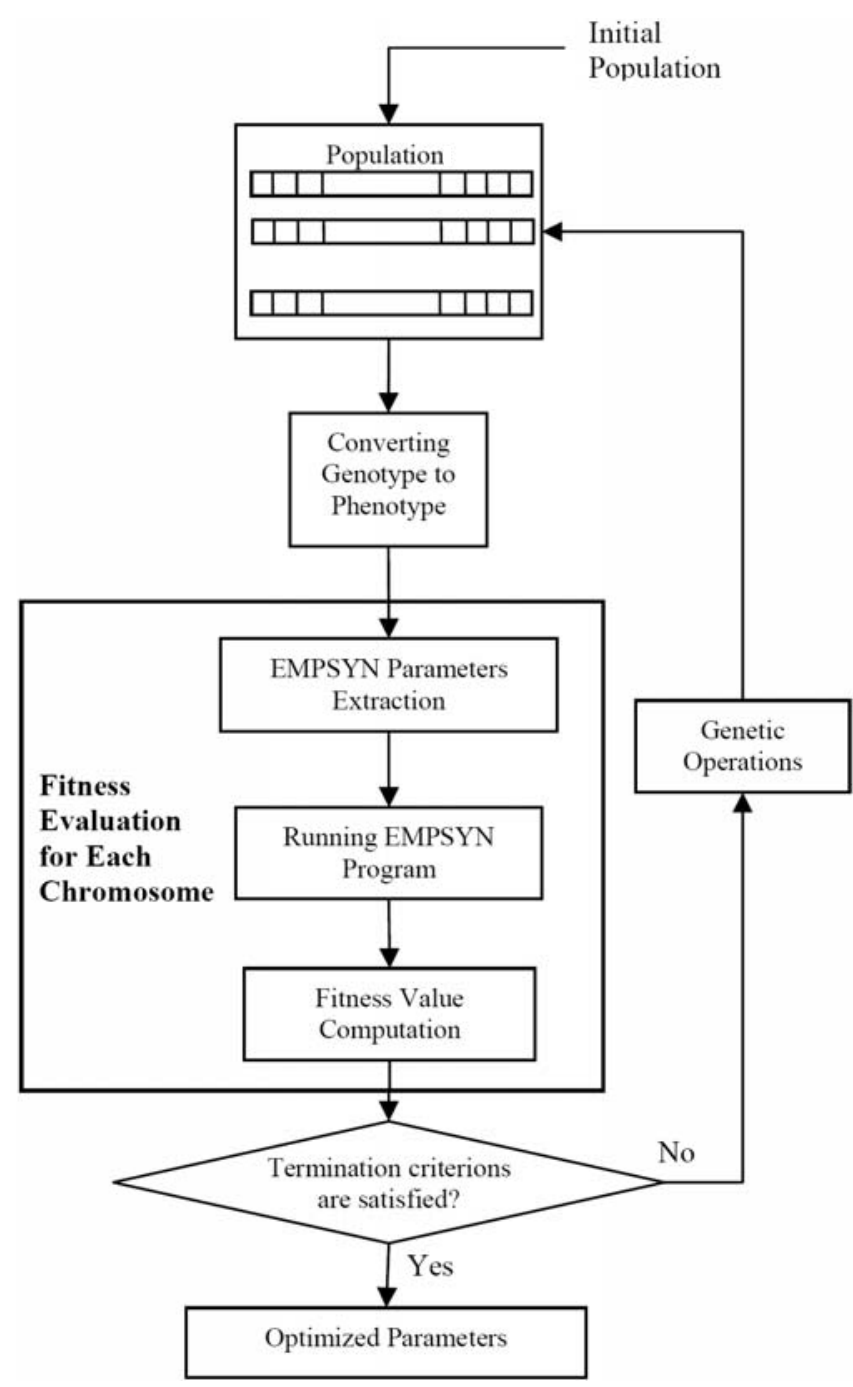

Figure 4. Proposed GA model flowchart.

to be genetic algorithm (GA). A generic algorithm is a computer simulation of natural evolutionary processes to solve search and optimization problems.

Genetic algorithm was initially developed by John Holland over the course of 1960s and 1970s and was extended by his student, David Goldberg (1989a, 1989b). The applicability of genetic algorithm in engineering problems stems in the efforts done by Goldberg. Genetic algorithm as an optimization procedure has also been successfully applied to structural design (Camp et al 1998).

Most genetic algorithms are variations of the simple genetic algorithm (SGA) proposed by Goldberg (1989a, 1989b). SGA includes three basic genetic operators: reproduction, crossover, and mutation. The objective of the reproduction is to keep chromosome strings with good fitness values and survive them into the next generation. Typically, based on the string's fitness, each string in the population is assigned to a probability of being selected as a parent string. The next generations of solution strings are developed from selected pairs of parent strings and the application of other operators such as crossover and mutation. A selected parent string is broken into segments through a crossover procedure and some of these segments are exchanged with corresponding segments of another parent string. The one-point crossover implemented in Goldberg's SGA, breaks each string of a selected parent string set into two segments and interchanges the second segment to create two new strings. Mutation is usually used as an insurance policy. It allows the possibility that non-existing features from both parent strings may be created and passed to their children. Without an operator of this type, some possibly important regions of the search space may never be explored. Genetic algorithms develop solutions based on the payoff or quality of the fitness of solutions strings. A scheme for properly evaluating the fitness is an important factor to gain the better result (Camp et al 1998).

Some investigators used GA in finding source parameters. Jimenez et al (2005) applied GA method in an inversion method to find earthquake source parameters and attenuation factors. $\mathrm{Wu}$ et al (2008) used the GA approach to find focal mechanism in Taiwan. Nicknam et al (2009) applied the GA approach for synthesizing the 2006 Silakhor earthquake located at western part of Iran. In this study, the GA technique is used as a tool for reducing the two types of above-mentioned uncertainties, inherently existing in seismological model parameters. The goal is achieved by means of calculating and reducing the differences between the $5 \%$ elastic response spectra corresponding to the synthesized time series and the observed data. The GA generates candidate solutions, here a list of seismological parameters, which are given to the EMPSYN program, for simulating the acceleration time histories, evolving the input parameters thus choosing the best set.

The binary representations of bit strings are used as a part of the proposed chromosome design. Each chromosome, containing model parameters, consists of several bit string parameters incorporated 
into the GA procedure used. The binary strings are converted into real numbers using equation (1).

$$
Z=Z_{\min }+\frac{Z_{\max }-Z_{\min }}{2^{n_{j}}-1} \times d
$$

$Z$ : phenotype of bit string; $Z_{\max }$ : maximum parameter value; $Z_{\min }$ : minimum parameter value; and $d$ : decimal value of bit string.

The main steps of the proposed GA-based algorithm are shown in the flowchart (see figure 4).

The initial population is generated randomly and the main GA loop is initiated with starting this population. Each chromosome in the population contains a seismological model parameter. These parameters are the objectives of the GA to be optimized. In each step, the population chromosomes (also known as individuals) are evaluated with the fitness function. The parameters are incorporated into the EMPSYN software program. The output of this stage is an acceleration time history from which the corresponding elastic response spectrum is calculated. The fitness value is inversely related to the difference between the two response spectra corresponding to the synthesized and observed spectra.

The mathematical form of error function evaluating the fitness of individuals in each generation for the two horizontal components $L, T$, and vertical component $V$, are as follows:

\section{Error_Func.}

$$
=\sqrt{\text { Err_L com. }+ \text { Err_ T com. }+ \text { Err_V com. }_{-}}
$$

Fitness_Func. $=\frac{1}{\text { Error_Func. }}$

where Err_L com. is the error value computed for $\mathrm{L}$ component between the synthesized and observed acceleration response spectra which is the sum of the squares of the errors at any period.

Err_T com. is the error value computed for $\mathrm{T}$ component between synthesized and observed acceleration response spectra which is the sum of the squares of the errors at any period.

Err_V com. is the error value computed for $\mathrm{V}$ component between synthesized and observed acceleration response spectra, which is the sum of the squares of the errors at any period.

The three-point crossover (reproduction) is used as the crossover operator. After the two parent chromosomes are selected, three random numbers, less than or equal to chromosome length, are generated and the bits associated with these numbers are used as the boundaries for dividing chromosomes into four sections. Thereafter, the second and forth sections of the two selected chromosomes are exchanged. Figure 6 demonstrates the crossover operation process (figure 5a).

A simple mutation operator is used, in which a random number less than or equal to the chromosome length is generated and the value of associated bit is flipped (figure 5b). The genetic algorithm will be terminated if the number of generations that population is no longer improved meets a specific number $\left(n_{g}\right)$.

\section{Simulating the Bam earthquake at far source sites}

The computer code EMPSYN (Hutchings 1988), originally written by Hutchings was used in this study. It calculates synthetic seismograms by numerically computing the discredited representation relation with empirical Green's functions (EGF). The formula it uses has the following form (Hutchings et al 2007):

$$
U(X, t)=\sum_{i=1}^{N} \frac{\mu_{i} A_{i} S\left(t^{\prime}\right)_{i}}{M_{0 i}^{e}} * e_{n}\left(X, t^{\prime}-t_{r}\right)_{i},
$$

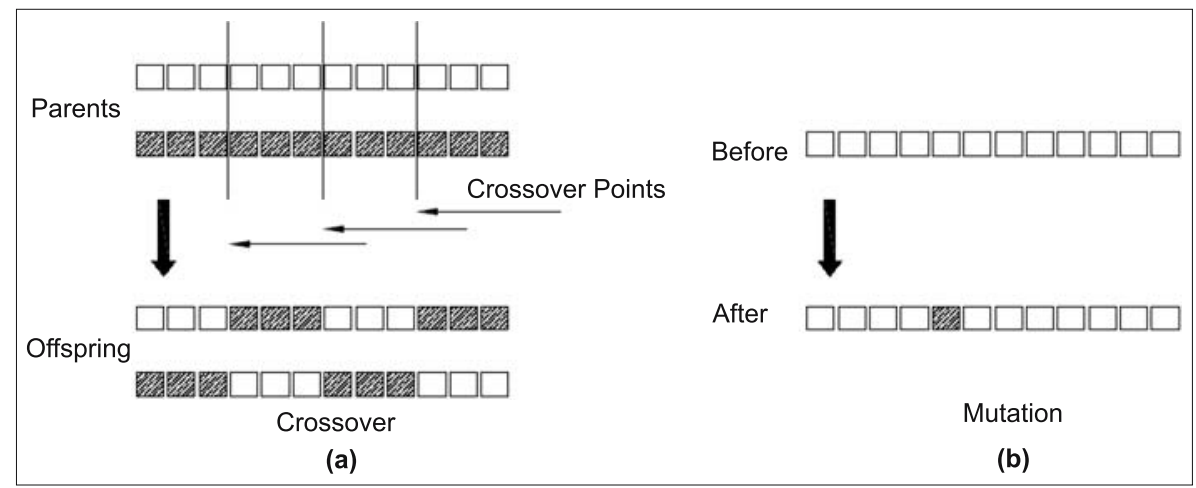

Figure 5. Genetic operators. 
Table 3. Comparison of hypocenter location and focal mechanism parameters for the 2003 Bam earthquake main shock estimated in this study by other references.

\begin{tabular}{lccccc}
\hline $\begin{array}{l}\text { Longitude } \\
\text { (deg.) }\end{array}$ & $\begin{array}{c}\text { Latitude } \\
(\text { deg. })\end{array}$ & $\begin{array}{c}\text { Depth } \\
(\mathrm{km})\end{array}$ & $\begin{array}{c}\text { Moment } \\
\text { magnitude } \\
(\mathrm{Mw})\end{array}$ & $\begin{array}{c}\text { Focal mechanism } \\
\text { (Strike, Dip, Rake) }\end{array}$ & Reference \\
\hline 58.365 & 29.050 & - & 6.5 & - & BHRC \\
58.240 & 29.100 & 15 & 6.6 & $172,59,167$ & Harvard CMT \\
58.266 & 29.010 & 14 & 6.5 & $174,88,178$ & NEIC \\
58.353 & 29.037 & 5.2 & 6.5 & $354,84,-178$ & \\
58.357 & 29.038 & 5.5 & 6.6 & $355,86,-178$ & Funning et al (2005) \\
58.356 & 29.040 & 6.4 & 6.6 & $355,86,-178$ & Talebian et al (2004) \\
58.294 & 28.864 & 5 & 6.1 & $180,30,90$ & \\
58.294 & 28.972 & 6 & 6.6 & $357,88,-166$ & This study (GA) \\
58.380 & 29.040 & 9 & 6.5 & $356,81,-174$ & \\
\hline
\end{tabular}

Table 4. Fault dimensions proposed by other references and those of this study.

\begin{tabular}{lcccc}
\hline & \multicolumn{3}{c}{ Funning et al (2005) } & \\
\cline { 2 - 4 } & Uniform slip & Variable slip & Variable slip and rake & This study (GA) \\
\hline Rupture length & $12.0 \mathrm{~km}$ & $12.0 \mathrm{~km}$ & $20.0 \mathrm{~km}$ & $14.91 \mathrm{~km}$ \\
Rupture width & 8.1 & $8.6 \mathrm{~km}$ & 15.0 & $7.82 \mathrm{~km}$ \\
Rupture area & $97.2 \mathrm{~km}^{2}$ & $103.2 \mathrm{~km}^{2}$ & $300 \mathrm{~km}^{2}$ & $116.6 \mathrm{~km}^{2}$ \\
\hline
\end{tabular}

where $X$ and $t$ are position and time in space relative to the hypocenter and the origin time of the synthesized earthquake. $N$ is the number of elements and $i$ denotes the values at an element. $A_{i}$ is the area of an element of the fault such that sum of all $A_{i}$ s equals the total rupture area. $\mu_{i}$ is the rigidity at an element. $S\left(t^{\prime}\right)_{i}$ is the desired slip function at an element analytically deconvolved with the step function. $e_{n}\left(X, t^{\prime}\right)_{i}$ is the recording of a small earthquake with effectively a step source time function, and interpolated to have a source and origin time at the location of the $i$ th element. $t^{\prime}$ is relative to the origin time of the synthesized earthquake. $t_{r}$ is the time that rupture reaches from the hypocenter to the element. It is the integral of radial distance from the hypocenter of the synthesized earthquake divided by the rupture velocity, which can be a function of position on the fault. $M_{0 i}^{e}$ is the scalar seismic moment of the source event, and $*$ stands for the convolution operator. $U$ has the same units as $e_{n}$ (Hutchings et al 2007).

The proposed genetic algorithm (GA) was applied to the simulation computer software, EMPSYN (Hutchings 1988) at a far source station, Mohammad-Abad, about $47 \mathrm{~km}$ far away from the causative fault, to find seismological parameters of the Bam earthquake. Population size was set to 200 , crossover rate to 0.8 and mutation rate to 0.08 by experience. Three-point crossover, as mentioned above, together with a roulette wheel selection was taken into use. The number of bits for each chromosome was set to $n_{j}=8$. The maximum number of generations used as the termination criterion was $n_{g}=50$ and finally, as will be explained later, 39 parameters are cooperated into the algorithm to be optimized. The well known Kostrov slip function with variable rise time and constant stress drop together with three aftershocks with magnitudes of 4.5-5.5 has been incorporated in the model. Also to check the validity of the estimated source parameters, they were used in simulation process of another far source station, Abaragh, using EGF method.

\section{Results and discussion}

We proposed a technique which permits the estimation of seismological parameters in the region under study. The 39 seismological model parameters are estimated and the uncertainties inherently existing in these parameters are minimized which are summarized as follows:

The number of parameters corresponding to the main shock are: 3 parameters for hypocenter location, 4 parameters for distances of fault edges from hypocenter, 1 parameter for the sub-fault dimension, 1 parameter for the magnitude, 3 parameters for the focal mechanism (Strike, Dip and Rake), 2 parameters for the ratio of rupture and healing velocity to shear velocity, and 4 parameters for input velocity. The upper and lower bounds of these parameters are selected based on the works previously done by other investigators such as 

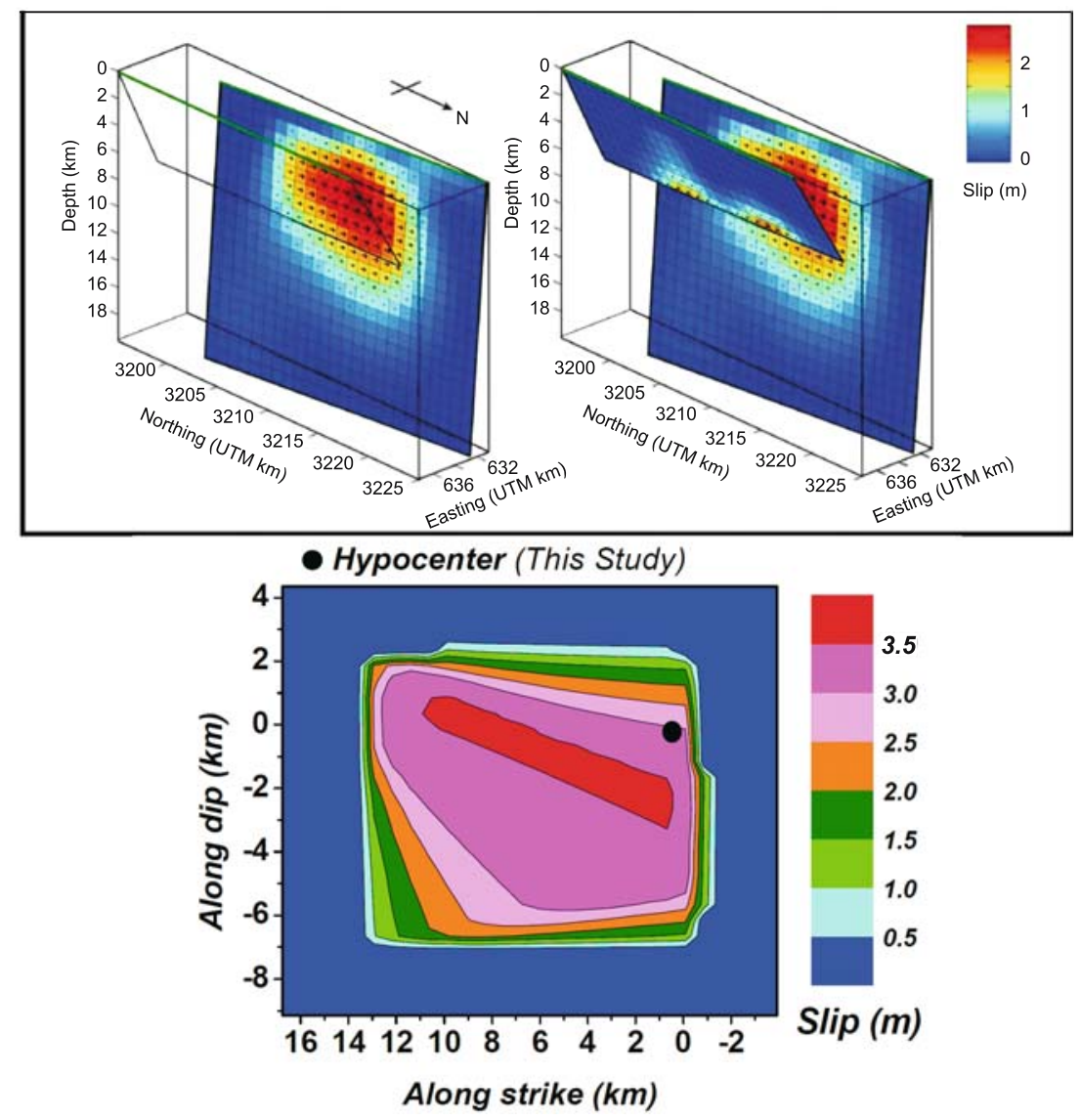

Figure 6. Rupture area, slip distribution and hypocenter demonstration of the Bam earthquake obtained by Funning et al (2005) (top) and this study (down).

Jackson et al (2006), Talebian et al (2004) and Funning et al (2005), in the 2003 Bam earthquake. Tables 3 and 4 illustrate the comparison of estimated seismological parameters with those of other investigators.

Kostrov slip function, with variable rise time, and constant stress drop are incorporated in the model for estimating the rupture area, slip distribution and hypocenter of the causative Bam earthquake fault and the results are compared with those of Funning et al (2005) (see figure 6).

The proposed genetic algorithm was used for solving the problem as an inversion tool to optimize the differences between estimated time series and those of recording. It gradually changes the parameters set to minimize the differences between elastic response spectra (5\% damping ratio) corresponding to the synthesized and observed data at Mohammad-Abad station. Figure 7(a and b) shows the observed and simulated acceleration time histories at Mohammad-Abad station respectively. Additionally, the elastic response spectra (with 5\% damping ratio) corresponding to the three components of simulated seismograms at this station along with those estimated by Funning et al (2005) are compared with the observed seismograms (see figure 7c). As is seen, our technique results in more agreement between the estimated and observed data than those of Funning et al (2005), confirming the reliability of our estimated seismological parameters (see figure 7c).

In order to validate the estimated time series and also the aforementioned source parameters, a forward simulation is made at Abaragh station located at about $52 \mathrm{~km}$ far away from the epicenter. The optimized parameters obtained from Mohammad-Abad station along with its specific EGFs, were incorporated in the model and the seismograms at Abaragh station were predicted without using inversion solution technique.

Good match of the estimated elastic response spectra and those of the observed data confirms the reliability of our technique in estimating the seismological parameters. Figure 8 (a and b) shows the observed and simulated acceleration time histories at Abaragh station respectively. In addition, the elastic response spectra corresponding to the synthesized strong motions, at this station, along with those of the observed data are shown. 

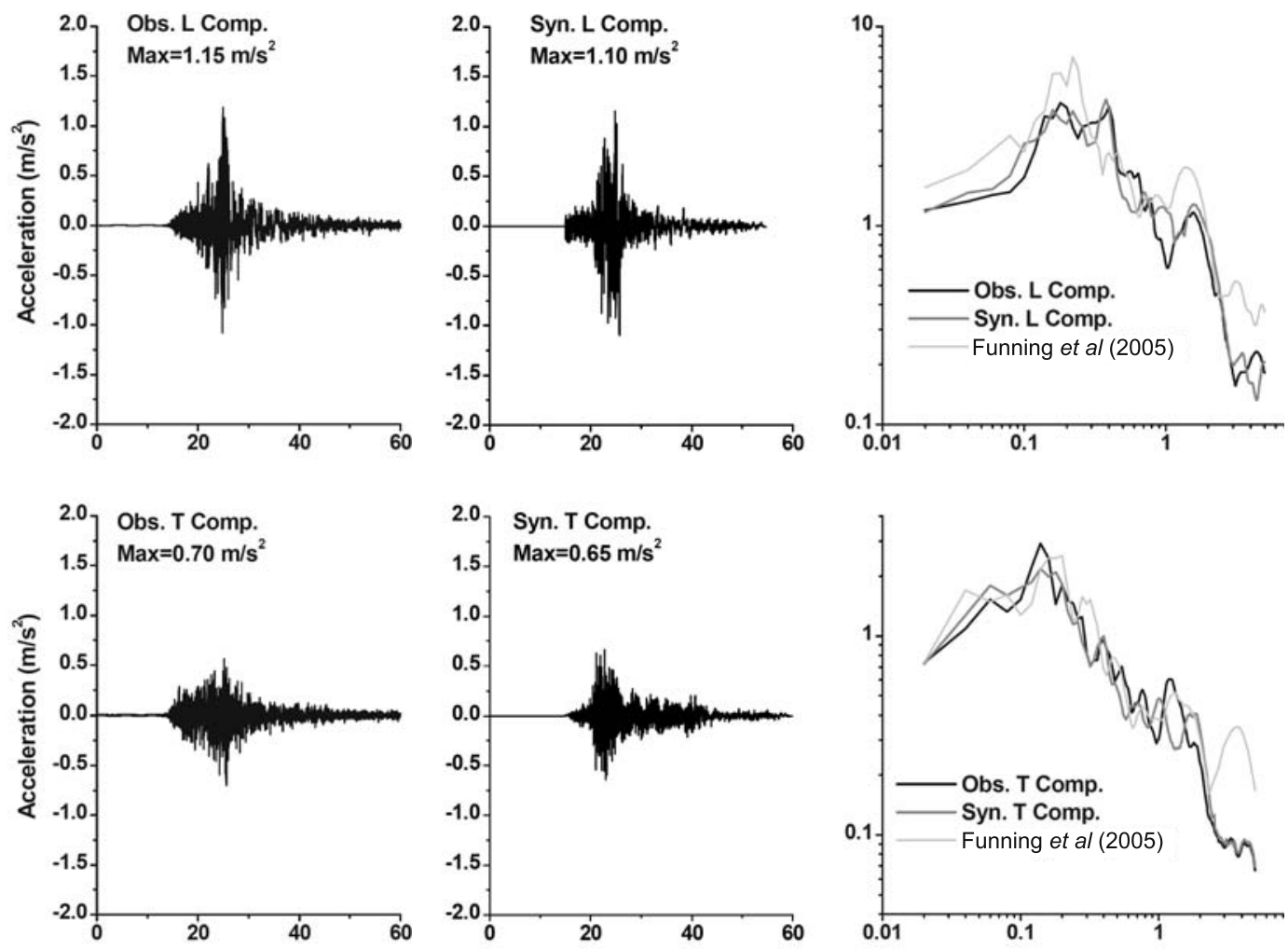

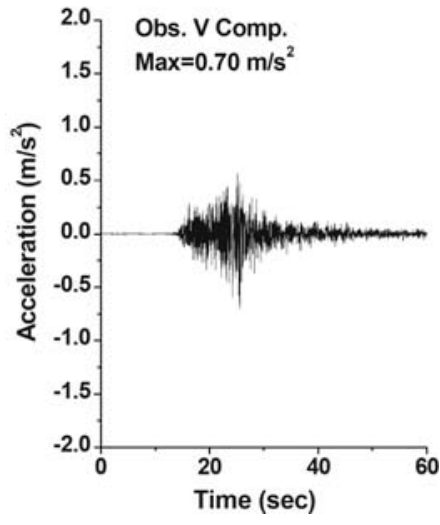

(a)

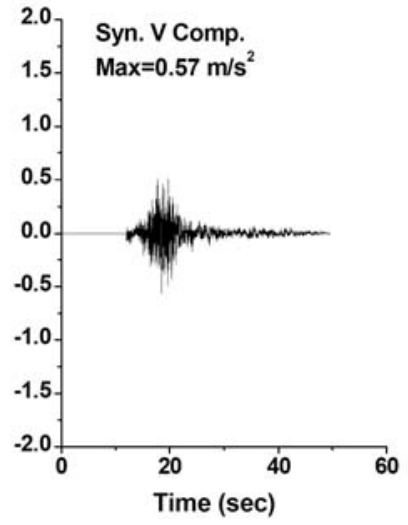

(b)

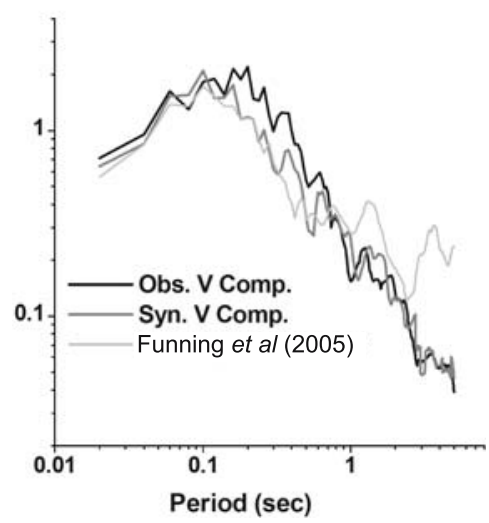

(c)

Figure 7. The observed seismograms at Mohammad-Abad station: (a) the synthesized strong motions, (b) the comparison illustration of observed synthesized and (c) those of Funning et al (2005), in terms of elastic response spectra (5\% damping ratio), at this station.

In the proposed GA process, the error value for each chromosome is calculated to find minimum error in each generation. Figure 9 shows the minimum error value, introduced before, in each generation. As can be seen, the differences between the estimated and observed data are gradually reduced as the generation number is increased, confirming the applicability and effectiveness of the technique in estimating the aforementioned seismological parameters. As is shown in figure 9, the curve becomes asymptotic to a horizontal line expressing the adequacy of synthesizing/modifying process.
As already mentioned, the parameter values previously estimated by other investigators were used as the upper-lower bounds (see tables 3 and 4). Table 5 gives the estimated hypocenter location and fault dimension.

Additionally, estimating the source parameters of main shock, e.g., rupture velocity, healing velocity, stress drop, fault duration, rise time and average slip constitute other results through this study (see table 6). This also confirms the potentiality and the applicability of our technique in estimating unknown information of the causative fault. Table 6 demonstrates the estimated parameters 

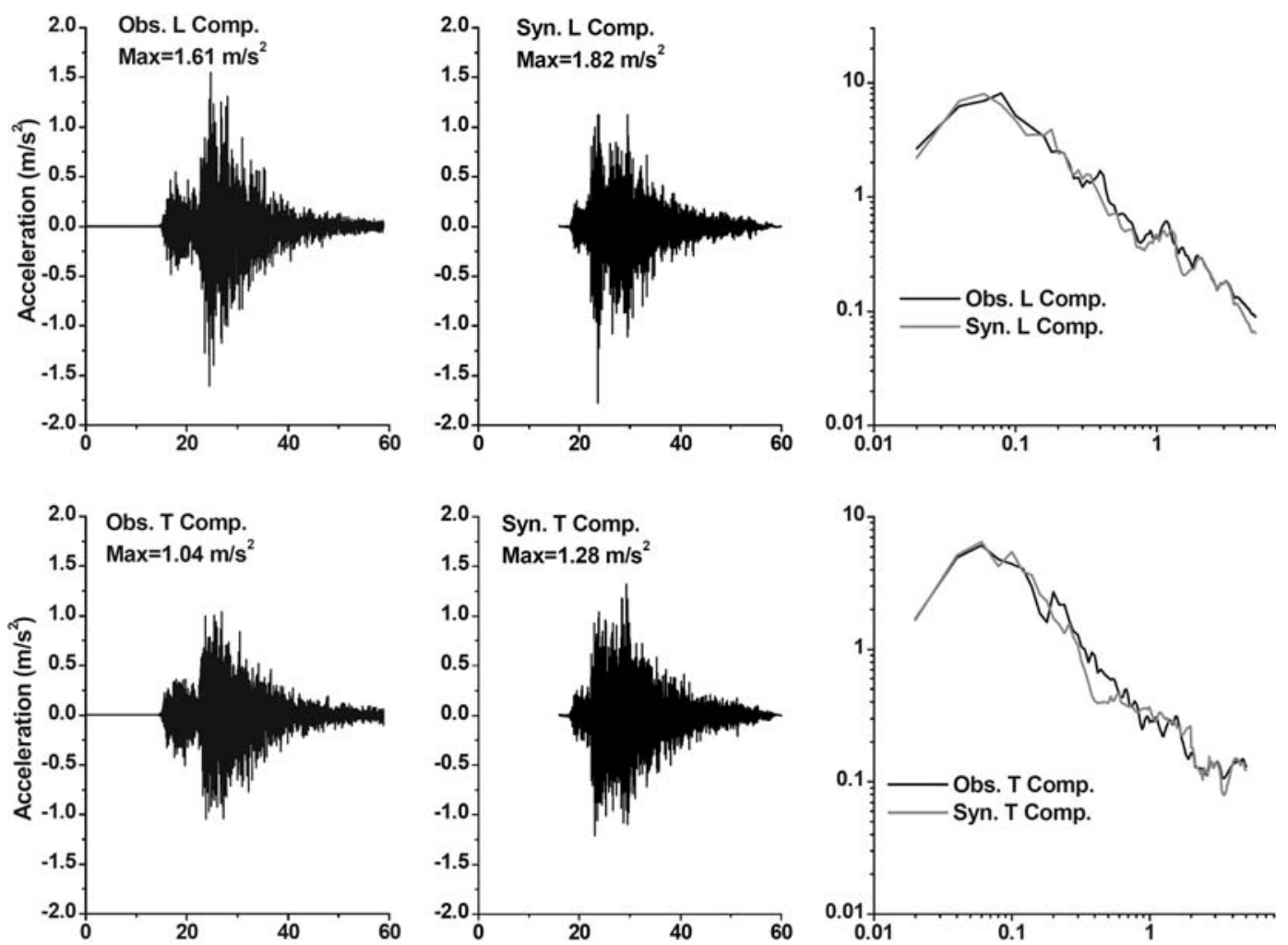

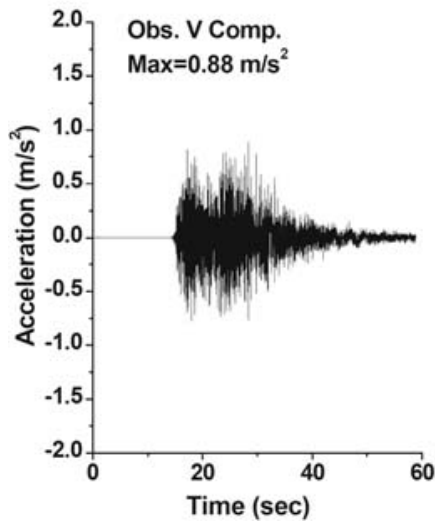

(a)

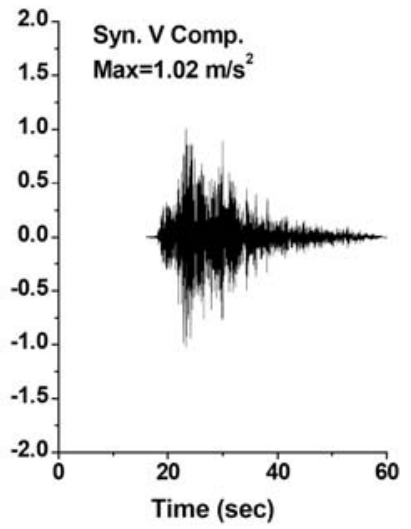

(b)

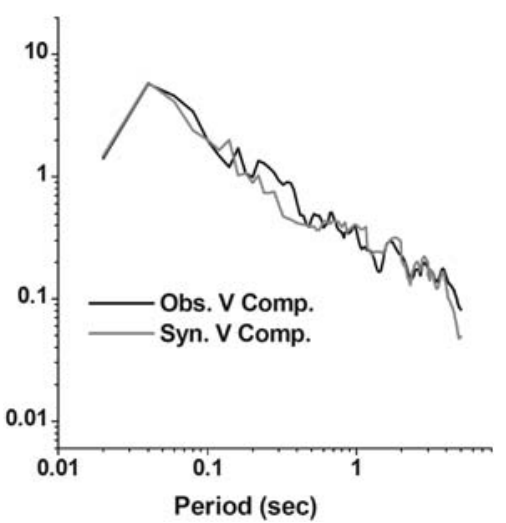

(c)

Figure 8. Illustration of the observed (a) and synthesized (b) strong motions at Abaragh station and comparison presentation of the synthesized strong motions with (c) those of the observed data, in terms of elastic response spectra (with $5 \%$ damping ratio), at this station.

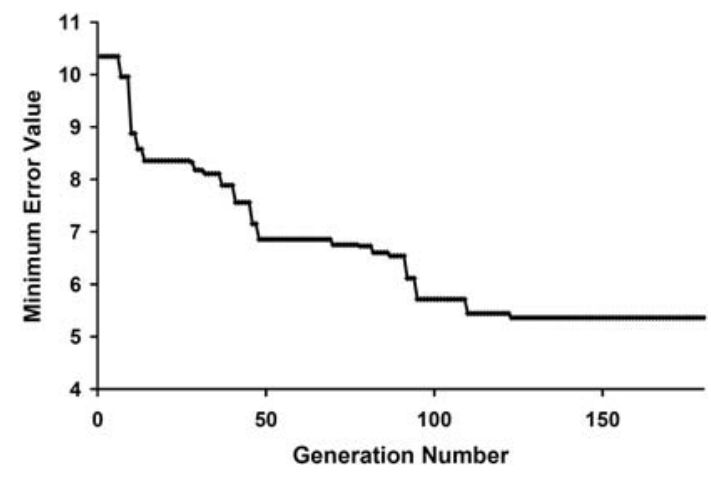

Figure 9. Minimum error value in each generation.
Table 5. Estimated fault characteristics using GA method in this study.

\begin{tabular}{cccccccc}
\hline \multicolumn{3}{c}{$\begin{array}{c}\text { Fault edges from } \\
\text { hypocenter (km) }\end{array}$} & & \multicolumn{3}{c}{ Hypocenter location } \\
\cline { 7 - 8 } \cline { 6 - 8 } Up & Right & Down & Left & & $\begin{array}{c}\text { Longitude } \\
\text { (deg.) }\end{array}$ & $\begin{array}{c}\text { Latitude } \\
\text { (deg.) }\end{array}$ & $\begin{array}{c}\text { Depth } \\
(\mathrm{km})\end{array}$ \\
\hline 2.50 & 13.97 & 7.32 & 0.94 & & 58.38 & 29.04 & 9 \\
\hline
\end{tabular}

and those suggested by Bouchon et al (2006). As is seen, the results of this study are close to those of Bouchon et al (2006). It is notable that Bouchon et al (2006) used uniform slip distribution. 
Table 6. Comparison between the estimated 2003 Bam earthquake source parameters obtained from GA technique and those of suggested by Bouchon et al (2006).

\begin{tabular}{|c|c|c|c|c|c|c|c|c|}
\hline & $\begin{array}{l}\text { Input } \\
\mathrm{P} \text { Vel. } \\
(\mathrm{km} / \mathrm{s})\end{array}$ & $\begin{array}{l}\text { Rupture } \\
\text { vel. } \\
(\mathrm{km} / \mathrm{s})\end{array}$ & $\begin{array}{l}\text { Healing } \\
\text { vel. } \\
(\mathrm{km} / \mathrm{sec})\end{array}$ & $\begin{array}{l}\text { Stress } \\
\text { drop } \\
(\mathrm{MPa}) \\
\end{array}$ & $\begin{array}{c}\text { Fault } \\
\text { dur. (s) }\end{array}$ & $\begin{array}{c}\text { Hypo. } \\
\text { slip (m) }\end{array}$ & $\begin{array}{l}\text { Hypo. rise } \\
\text { time (sec) }\end{array}$ & $\begin{array}{l}\text { Average } \\
\text { slip }(\mathrm{m})\end{array}$ \\
\hline $\begin{array}{l}\text { This study } \\
\text { (GA) }\end{array}$ & $\begin{array}{l}\mathrm{Vp}=4.09+0.05 * H_{z} \\
H_{z}>28 \mathrm{~km} \\
\mathrm{Vp}=5.5\end{array}$ & $\mathrm{Vr}=0.82 * \mathrm{Vs}$ & $\mathrm{Vh}=0.97 * \mathrm{Vr}$ & 21.2 & 7.4 & 2.7 & 0.9 & 2.8 \\
\hline $\begin{array}{l}\text { Bouchon } \\
\text { et al (2006) }\end{array}$ & $\begin{array}{l}5.30-6.17 \\
\text { Over the fault }\end{array}$ & $\mathrm{Vr}=0.92 * \mathrm{Vs}$ & - & - & - & 2.0 & 0.8 & 2.0 \\
\hline
\end{tabular}

(a)

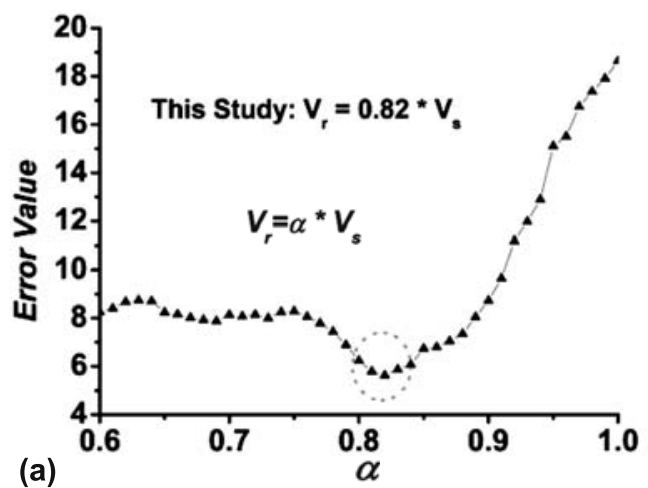

Figure 10. Sensitivity analysis for variation of rupture (a) and healing velocity (b) separately.

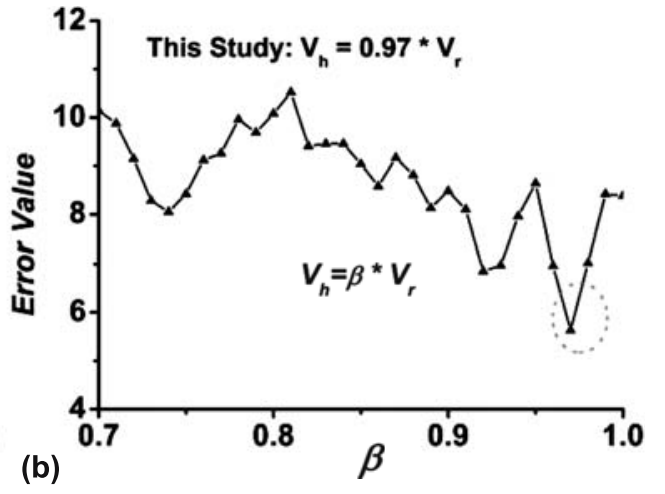

(b)

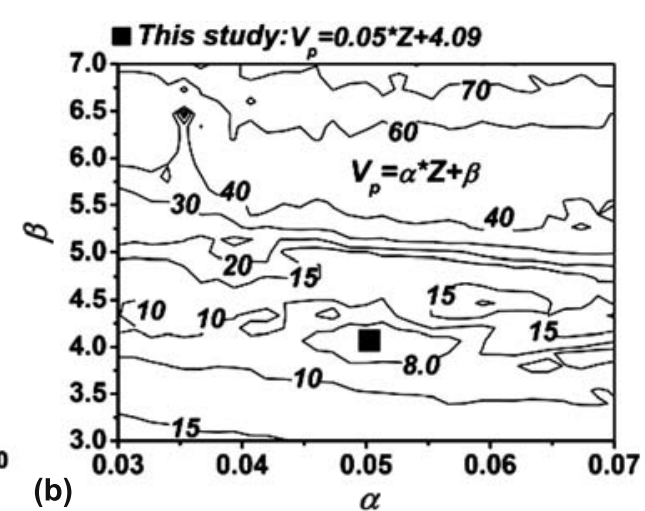

Figure 11. Sensitivity analysis presenting: the variation of rupture and healing velocity (a) and the variation of P-wave velocity in depth (b).

\section{Sensitivity analysis of model parameters}

A sensitivity analysis is performed for recognizing the influence of model parameter changes on the simulated seismograms. For this purpose, the aforementioned model parameters such as rupture and healing velocities, epicenter location, focal mechanism (Strike and Dip), P-wave velocity in depth, fault length and width and finally hypocenter location on the rupture area are changed and their influence on the error values are calculated. The error value is defined as the difference between simulated data and those of observed time series, in terms of elastic response spectra with $5 \%$ damping ratio (see equation 2).

For this purpose, the error value (equation 2) created in the simulated time series, caused by each of the above-mentioned model parameters, is calculated against the variation of that parameter while the remainder estimated parameters are kept constant. Figure 10(a) clearly shows the influence of Alpha variation, rupture to shear wave velocity ratio, on the error value demonstrating the 

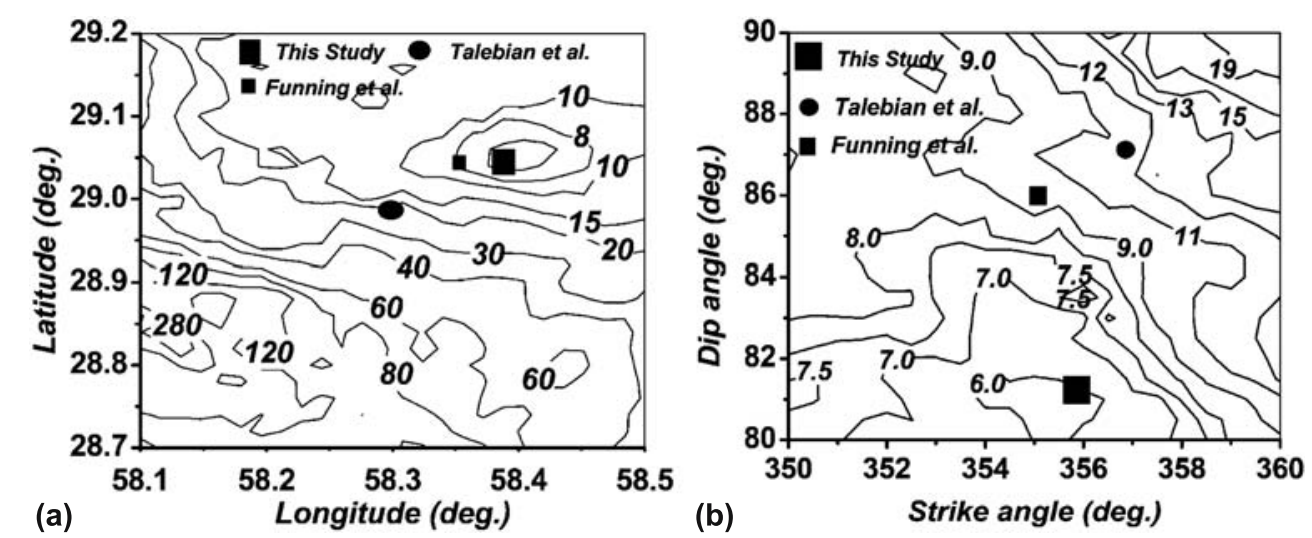

Figure 12. Sensitivity analysis presenting: the variation of epicenter location (a) and the variation of focal mechanism, Strike and Dip angle (b).
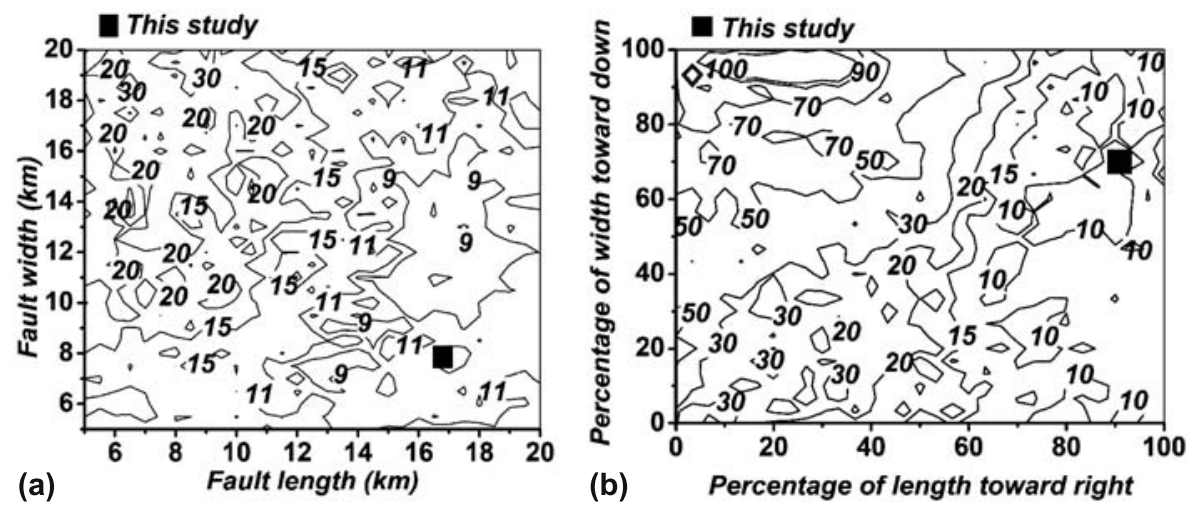

Figure 13. Sensitivity analysis presentation: the variation of fault dimensions (a) the variation of hypocenter location on fixed rupture area (b).

minimum value, 0.82. An alpha value of 0.92 , for Bam earthquake is previously suggested by Bouchon et al (2006) by using uniform slip distribution while that of our model is variable. The variation of healing velocity ratio to rupture velocity (Beta) is also shown in figure 10(b). This parameter has not previously been reported for this earthquake and a value of 0.97 is estimated through this study.

Figures 11, 12 and 13, demonstrate the influence of variation of: rupture and healing velocity, epicenter location, P-wave velocity in depth, focal mechanism (Strike and Dip), fault dimension, and hypocenter location on the error value respectively. The contours shown in the figures demonstrate error values against the variation of parameters written on the axes. The contours shown in the figures 11 through 13, visibly highlight the influences of model parameter variations on the error value (equation 2). Additionally, the influence of hypocenter location variation on the fixed rupture area, $116.6 \mathrm{~km}^{2}$, is traced (see figure $13 \mathrm{~b}$ ).

Having a look at figure 12, it is clear that our results are more close to those of Funning et al
(2005) rather than the results of Talebian et al (2004).

\section{Conclusion}

In this article, a technique is proposed which allows the prediction of seismograms due to main event, at selected station as a result of inversion solution at other station. The well known EGF method is used to synthesize acceleration time histories. A GA approach is developed to optimize the seismological model parameters by means of minimizing the differences between estimated seismograms and those of observed data. Generally speaking, 39 seismological model parameters such as: rupture and healing velocities, epicenter location, focal mechanism (Strike and Dip), P-wave velocity in depth, fault dimensions and hypocenter location are optimally estimated. The optimization is objected to minimize the differences between the elastic response spectra (5\% damping ratio) corresponding to the synthesized time series and those of the observed data. The simulated three 
component seismograms along with those of other investigators, previously done, are compared with the recorded data signifying more agreement of our results.

The potentiality of proposing GA technique to reduce the uncertainties existing in the seismological parameters and thus confirming the reliability of the estimated model parameters is discussed and graphically shown.

The aforementioned seismological parameters are estimated by means of an inversion solution technique used at Mohammad-Abad station and the three components of acceleration time histories at Abaragh station are straightforward predicted. Both selected stations are sufficiently far away from the causative fault so as the results are not strongly influenced by the near source problems. Good match of our results confirm the potentiality and applicability of the proposed technique. Some of the estimated parameters in this study are reported by other researchers and many of them aren't reported previously. As shown in the paper, our results are close to the results of other researchers such as Funning et al (2005), Talebian et al (2004) and Bouchon et al (2006). Additionally, it was shown that, our technique has the ability of estimating some unreported source parameters of the main shock.

A sensibility analysis is performed for recognizing the influence of each model parameter changes on the error values of simulated seismograms through which the optimal parameter values are determined. The error values, in terms of the differences between the elastic response spectra (with 5\% damping ratio) corresponding to the estimated time series, are compared with those of the other investigators such as Funning et al (2005), Talebian et al (2004) and Bouchon et al (2006).

Our inferred source parameters provide the basis for predicting main shock shaking and guiding retrofitting efforts for the existing important buildings such as historical adobe buildings at Arg-e-Bam site which were damaged during the 2003 Bam earthquake.

It is noticeable that, in spite of the fact that the estimated elastic response spectra corresponding to the six components of synthesized strong motions are comparatively in good agreement with those of the observed data, it is not claimed that the proposed technique ends with the results free from aleatoric and epistemic uncertainties previously discussed.

\section{Acknowledgements}

Many thanks to Prof. Hutchings for kindly offering his valuable simulation codes and also to Dr Yasin
Fahjan, for giving us the EMPSYN FORTRAN computer software codes. We also thank Dr Mirzaei from BHRC for giving the valuable information of the Bam earthquake.

\section{References}

Aki K 1968 Seismic displacements near a fault; J. Geophys. Res. 73 5359-5376.

Anderson J G 2001 Handbook of Earthquake and Engineering Seismology, Chapter 57, University of Nevada, Reno, NV, USA.

Beresnev I A and Atkinson G M 1997 Modeling finite-fault radiation from the $\omega^{n}$ spectrum; Bull. Seismol. Soc. Am. 87(1) 67-84.

Beresnev I A and Atkinson G M 2002 Source parameters of earthquakes in eastern and western North America based on finite-fault modeling; Bull. Seismol. Soc. Am. 92 695-710.

Bernard P and Madariaga R 1984 A new asymptotic method for the modelling of near field accelerograms; Bull. Seismol. Soc. Am. 74 539-558.

Beroza G C and Spudich P 1988 Linearized inversion for fault rupture behavior: Application to the 1984 Morgan Hill, California earthquake; J. Geophys. Res. 93 6275-6296.

Bouchon M 1981 A simple method to calculate Green's functions for elastic layered media; Bull. Seismol. Soc. Am. 71 959-971.

Bouchon M, Hatzfeld D, Jackson J A and Haghshenas E 2006 Some insight on why Bam (Iran) was destroyed by an earthquake of relatively moderate size; Geophys. Res. Let. 33 L09309, doi:10.1029/2006GL025906.

Building and Housing Research Center (BHRC), Tehran, Iran (http://www.bhrc.ir).

Boore D M 1983 Stochastic simulation of high-frequency ground motions based on seismological models of the radiated spectra; Bull. Seismol. Soc. Am. 73 1865-1894.

Brune J N 1970 Tectonic stress and the spectra of seismic shear waves from earthquakes; J. Geophys. Res. 75 4997-5010.

Camp C, Pezeshk S and Cao G 1998 Optimized design of two-dimensional structure using a genetic algorithm; J. Struct. Eng. 124(5) 551-559.

Courboulex F, Singh S K, Pacheco J F and Ammon C J 1997 The 1995 Colima-Jalisco, Mexico, earthquake ( $\mathrm{Mw} 8)$ : A study of the rupture process; Geophys. Res. Lett. 24 1019-1022.

EERI Special Earthquake Report 2004 Earthquake Engineering Research Institute (EERI) Preliminary Observations on the Bam, Iran, Earthquake of December 26, 2003.

Frankel A, Fletcher J, Vernon F, Haar L, Berger J, Hanks T and Brune J 1986 Rupture characteristic and tomographic source imaging of $\mathrm{ML} \sim 3$ earthquakes near Anza, Southern California; J. Geophys. Res. 91 12,633-12,650.

Funning G J, Parsons B and Wright T J 2005 Surface displacements and source parameters of the 2003 Bam (Iran) earthquake from Envisat advanced synthetic aperture radar imagery; J. Geophys. Res. 110 B09406, doi: 10.1029/2004JB003338.

Gallovic F and Brokesova J 2007 Hybrid k-squared source model for strong motion simulations: An introduction; Phys. Earth Planet. Interiors 160 34-50.

Goldberg D E 1989a Genetic algorithms in search, optimization, and machine learning (Reading, MA: AddisonWesley). 
Goldberg D E 1989b Sizing populations for serial and parallel genetic algorithms; In: Proc. 3rd Int. Conf. on Genetic Algorithms (ed.) Schaffer J D, Los Altos, CA: Morgan Kaufmann, 70-79.

Hartzell S 1978 Earthquake aftershocks as Green's functions; J. Geophys. Res. 5 1-4.

Haskell N A 1969 Elastic displacements in the near-field of a propagating fault; Bull. Seismol. Soc. Am. 59 865-908.

Hutchings L 1988 Modeling strong earthquake ground motion within earthquake simulation program EMPSYN that utilizes empirical Green's functions, UCRL-ID-105890, Lawrence Livermore National Laboratory, Livermore, California, 122.

Hutchings L 1991 Prediction of strong ground motion for the 1989 Loma Prieta earthquake using empirical Green's functions; Bull. Seismol. Soc. Am. 81 88-121.

Hutchings L 1994 Kinematic earthquake models and synthesized ground motion using empirical Green's functions; Bull. Seismol. Soc. Am. 84 1028-1050.

Hutchings L and Wu F T 1990 Empirical Green's functions from small earthquakes - A waveform study of locally recorded aftershocks of the San Fernando earthquake; J. Geophys. Res. 95 1187-1214.

Hutchings L, Wu F T, Rau R J, Jarpe S, Kasameyer P and Foxall W 1997 Strong ground motion synthesis along the Sanyi-Tungshih-Puli seismic zone using empirical Green's functions, Central Weather Bureau 100th Anniversary International Conference on Weather Analysis and Forecasting Taipei, Taiwan.

Hutchings L, Ioannidou E, Foxall W and Voulgaris N 2007 A physically based strong ground-motion prediction methodology; Application to PSHA and the 1999 $\mathrm{Mw}=6.0$ Athens earthquake; Geophys. J. Int. $\mathbf{1 6 8}$ $659-680$.

International Institute of Earthquake Engineering and Seismology, 2004.

Institute of Geophysics, University of Tehran 2004 (http://geophysics.ut.ac.ir/En/).

Iranian Code of Practice for Seismic Resistant Design of Buildings (Standard No. 2800). Building and Housing Research Center (2006).

Irikura K 1983 Semi-empirical estimation of strong ground motions during large earthquakes; Bull. Disaster Res. Inst. 33 63-104.

Jackson J, Bouchon M, Fielding E, Funning G, Ghorashi M, Hatzfeld D et al 2006 Seismotectonic, rupture process, and earthquake-hazard aspects of the 2003 December 26 Bam, Iran, earthquake; Geophys. J. Int. 166 1270-1292.

Jarpe S P and Kasameyer P W 1996 Validation of a procedure for calculation broadband strong motion time histories from empirical Green's functions; Bull. Seismol. Soc. Am. 86 1116-1129.

Jimenez A, Garcia M J and Romacho M D 2005 Simultaneous inversion of source parameters and attenuation factor using genetic algorithm; Bull. Seismol. Soc. Am. 95(4) 1401-1411.

Joyner W B and Boore D M 1986 On simulating large earthquakes by Green's-function addition of smaller earthquakes, Earthquake Source Mechanics; American Geophysical Monograph 6 269-274.
Kanamori H, Jennings P C, Singh S K and Astiz L 1993 Estimation of strong ground motions is Mexico City expected for large earthquakes in the Guerrero seismic gap; Bull. Seismol. Soc. Am. 83 811-829.

Lam N, Wilson J and Hutchinson G 2000 Generation of synthetic earthquake accelerograms using seismological modelling: A review, J. Earthquake Engineering 4(3) 321-354.

Plicka V 2003 Modelling of finite-extent seismic sources by empirical Green's functions, Summary of Ph.D. Thesis, Charles University, Faculty of Mathematics and Physics, Department of Geophysics.

Plicka V and Zahradnik J 2002 The EGF method for dissimilar focal mechanisms: The Athens 1999 earthquake; Tectonophys. 359 81-95.

Mori J and Frankel A 1990 Source parameters for small events associated with the 1986 North Palm Springs, California, earthquake determined using empirical Green functions; Bull. Seismol. Soc. Am. 80 278-295.

Mueller C S 1985 Source pulse enhancement by deconvolution of an empirical Green's function; Geophys. Res. Lett. $1233-36$.

Naeim F, Alimoradi A and Pezeshk S 2004 Selection and scaling of ground motion time histories for structural design using genetic algorithms; Earthquake Spectra 20(2) 413-426.

National Earthquake Information Center.

NEHRP recommended provisions for seismic regulations for new buildings and other structures 2000 Edition, Prepared by the Building Seismic Safety Council for the Federal Emergency Management Agency, Washington D.C., 2001.

Nicknam A, Abbasnia R, Eslamian Y and Bozorgnasab M 2009 Extrapolating strong ground motion of Silakhor earthquake (ML 6.1), Iran, using EGF approach based on Genetic algorithm; Can. J. Earth Sci. 46(11) 801-810, doi:10.1139/E09-052.

Spudich P and Frazer N 1984 Use of ray theory to calculate high-frequency radiation from earthquake sources having spatially variable rupture velocity and stress drop; Bull. Seismol. Soc. Am. 74 2061-2082.

Talebian M, Fielding E J, Funning G J, Ghorashi M, Jackson J A and Nazari H 2004 The 2003 Bam (Iran) earthquake: Rupture of a blind strike-slip fault; J. Geophys. Res. 31 L11611, doi: 10.1029/2004GL020058.

Valle'e M 2004 Stabilizing the Empirical Green function analysis: Development of the projected Landweber method; Bull. Seismol. Soc. Am. 94(2) 394-409.

Velasco A A, Ammon C J and Lay T 1994 Empirical Green function deconvolution of broadband surface waves: Rupture directivity of the 1992 Landers, California $(\mathrm{Mw}=7.3) ;$ Bull. Seismol. Soc. Am. 84 735-750.

Wennerberg L 1990 Stochastic summation of empirical Green's functions; Bull. Seismol. Soc. Am. 80 1418-1432.

Wu F T 1978 Prediction of strong ground motion using small earthquakes; 2nd International Microzonation Conference, San Francisco 2 701-704.

Wu Y M, Zhao L, Chang C H and Hsu Y J 2008 Focalmechanism determination in Taiwan by genetic algorithm; Bull. Seismol. Soc. Am. 98(2) 651-661. 